\title{
Features Selection For Efficient Data Center Disaster Management
} Approach

Noor Hayati Mohd Zain, Norafida Ithnin*

Faculty of Computing, Universiti Teknologi Malaysia, 81310 UTM Johor Bahru, Johor, Malaysia

*Corresponding author: afida@utm.my

\begin{abstract}
Data center is a place where a lot of data and information stored together. Pooling all data in one large place called data center will make management work become complex and hard to be manage. Threats become one major problem which can cause disaster to data center. Disaster management is one important step that need to be done in reducing disaster impact and disaster loss when threats attacked or strike to data center. This paper presents on features selection for efficient Data Center Disaster Management (DCDM) approach as one propose solution. The features of disaster management is listed and compared in evaluating the suitable DCDM mechanism to improve the previous disaster management processes. Based on all selected features, a comparison of features from existing DCDM approach are analyzed and the selected features was identified toward a better development of the new DCDM approach.
\end{abstract}

Keywords: Data center; threats; disaster management; features of DCDM

(C) 2017 Penerbit UTM Press. All rights reserved

\subsection{INTRODUCTION}

Theoretically, data center is known as a server farm or a computer room; it is where the majority of an enterprise servers and storage are located, operated and managed [1]. A current trend in data center architecture is the use of large scale and modular data centers composed of shipping containers filled with servers. A business may own and operate its own data centers, or a data center may be operated by a service provider that in turn rents shares of its resources to other businesses. With the increasing age of big data evolution, the function of data center become complex and hardly manage. This is because of the high demand by end user nowadays in using many websites application such as Facebook, Gmail, Amazon, and many more that closely related with data center mechanism. Massive demanding on data center services can give a lot of problems to data center management. This situation can cause heavy incident or called disaster event to data center application. One of the issue that can cause disaster to data center is through threats attack. There are many kind of threats strike data center and cause disaster to it.

\subsection{THEORETICAL FOUNDATION OF THE STUDY}

The data center is an essential corporate asset that connect all servers, applications and storage services. As such, the data center is a key component that needs to be planned and managed carefully to meet the growing performance demands of users and application [2]. This paper present an overview of data center disaster management approach as one propose solution for reducing disaster effect in future that cause by threats through selected features list.

\section{Data Center Issues}

Data center applications increasingly involve access to massive data sets, real-time data mining, and streaming media delivery that place heavy demands on the storage infrastructure. Efficient access to large amounts of storage necessitates not only high performance file systems but also high performance storage technologies such as solid state storage (SSD) media. Streaming large amounts of data (from disks or SSDs) also requires high-speed and low-latency networks. In clustered applications, the inter-process communication (IPC) often involves rather small messages but with very low-latency requirements. These applications may also use remote main memories as "network caches" of data and thus tax the networking capabilities [3]. All these factors can closely related reason to increase the data center disaster management from disaster incident. That is why, data center disaster management is very important matter to be figure out by an authorize side for save and secure data center condition in future. 
Table 1 List of issues in data center

\begin{tabular}{|l|l|}
\hline Issues & Explanation \\
\hline Configuration management & $\begin{array}{l}\text { Required at multiple levels, ranging from servers to server enclosures } \\
\text { to the entire data center }\end{array}$ \\
\hline Increasing size of data centers & $\begin{array}{l}\text { High utility costs and also leads to significant challenges in power } \\
\text { and thermal management }\end{array}$ \\
\hline $\begin{array}{l}\text { Unsustainable current, power, and thermal densities, and inefficient } \\
\text { usage of data center space }\end{array}$ & $\begin{array}{l}\text { Impacts performance and thus requires a combined treatment of } \\
\text { power and performance }\end{array}$ \\
\hline Increase attractive targets of attack & $\begin{array}{l}\text { An isolated vulnerability can be exploited to impact a large number } \\
\text { of customers and/or large amounts of sensitive data }\end{array}$ \\
\hline Virtualized outsourced environment & $\begin{array}{l}\text { The intruders could well be those sharing the same physical } \\
\text { infrastructure for their business purposes }\end{array}$ \\
\hline Basic virtualization techniques & $\begin{array}{l}\text { Enhance vulnerabilities since the flexibility provided by } \\
\text { virtualization can be easily exploited for disruption and denial of } \\
\text { service }\end{array}$ \\
\hline
\end{tabular}

Refer to Table 1, the issue mention about configuration management is a vital component for the smooth operation of data centers but not received much attention in literature. As the complexity of the servers, operating environments, and applications increases, effective realtime management of large heterogeneous data centers becomes quite complex [3].

The increasing size of data centers not only results in high utility costs [4] but also leads to significant challenges in power and thermal management [5]. For example, it is estimated that the total data center energy consumption as a percentage of total US energy consumption doubled between 2000 and 2007 and is set to double yet again by 2012. The high utility costs and environmental impact of such an increase are reasons enough to address power consumption. Additionally, high power consumption also results in unsustainable current, power, and thermal densities, and inefficient usage of data center space.

As data centers increase in size and criticality, they become increasingly attractive targets of attack since an isolated vulnerability can be exploited to impact a large number of customers and/or large amounts of sensitive data. Thus a fundamental security challenge for data centers is to find workable mechanisms that can reduce this growth of vulnerability with size.

Basically, the security must be implemented so that no single compromise can provide access to a large number of machines or large amount of data. Another important issue is that in a virtualized outsourced environment, it is no longer possible to speak of "inside" and "outside" of data center - the intruders could well be those sharing the same physical infrastructure for their business purposes [3].

Finally, the basic virtualization techniques themselves enhance vulnerabilities since the flexibility provided by virtualization can be easily exploited for disruption and denial of service. For example, any vulnerability in mapping VM level attributes to the physical system can be exploited to sabotage the entire system.

The data center is an essential corporate asset that connect all servers, applications and storage services. As such, the data center is a key component that needs to be planned and managed carefully to meet the growing performance demands of users and application [2]. This paper present an overview of data center disaster management approach as one propose solution for reducing disaster effect in future that cause by threats through selected features list.

\section{Data Center Issues}

Data center applications increasingly involve access to massive data sets, real-time data mining, and streaming media delivery that place heavy demands on the storage infrastructure. Efficient access to large amounts of storage necessitates not only high performance file systems but also high performance storage technologies such as solid state storage (SSD) media. Streaming large amounts of data (from disks or SSDs) also requires high-speed and low-latency networks. In clustered applications, the inter-process communication (IPC) often involves rather small messages but with very low-latency requirements. These applications may also use remote main memories as "network caches" of data and thus tax the networking capabilities [3]. All these factors can closely related reason to increase the data center disaster management from disaster incident. That is why, data center disaster management is very important matter to be figure out by an authorize side for save and secure data center condition in future.

Refer to Table 1, the issue mention about configuration management is a vital component for the smooth operation of data centers but not received much attention in literature. As the complexity of the servers, operating environments, and applications increases, effective realtime management of large heterogeneous data centers becomes quite complex [3].

The increasing size of data centers not only results in high utility costs [4] but also leads to significant challenges in power and thermal management [5]. For example, it is estimated that the total data center energy consumption as a percentage of total US energy consumption doubled between 2000 and 2007 and is set to double yet again by 2012. The high utility costs and environmental impact of such an increase are reasons enough to address power consumption. Additionally, high power consumption also results in unsustainable current, power, and thermal densities, and inefficient usage of data center space.

As data centers increase in size and criticality, they become increasingly attractive targets of attack since an isolated vulnerability can be exploited to impact a large number of customers and/or large amounts of sensitive data. Thus a fundamental security challenge for data centers is to find workable mechanisms that can reduce this growth of vulnerability with size.

Basically, the security must be implemented so that no single compromise can provide access to a large number of machines or large amount of data. Another important issue is that in a virtualized outsourced environment, it is no longer possible to speak of "inside" and "outside" of data center - the intruders could well be those sharing the same physical infrastructure for their business purposes [3].

Finally, the basic virtualization techniques themselves enhance vulnerabilities since the flexibility provided by virtualization can be easily exploited for disruption and denial of service. For example, any vulnerability in mapping VM level attributes to the physical system can be exploited to sabotage the entire system. 
Threats

Threats become one of the enemy for data center safety. It is a dangerous matter for all organization or companies or agency service provider that belongs data center in their business management. Good precaution need to be taken to avoid bad incident or disaster happen to their work later on. That is why disaster management become one important step to be implement to reduce threats or disasters overwhelm. The threats types relate to data center can be seen in Table 2 .

Table 2 Type of threats to data center [6]

\begin{tabular}{|l|l|}
\hline Type of threats & Effect \\
\hline Viruses & Damages worth £1.8bn in 12 days on the internet in 2003 \\
\hline Virus back doors & Hidden after-effects with potentially devastating impact \\
\hline Application-specific hacks & Advanced SQL injection could be stealing users data \\
\hline Phishing & Duped end-users could lose faith in IT systems \\
\hline Blended attacks & Criminals use multiple methods to beat even the best security \\
\hline Air temperature & $\begin{array}{l}\text { Equipment failure and reduce equipment life span from temperature above specification and/or } \\
\text { drastic temperature changes }\end{array}$ \\
\hline Humidity & $\begin{array}{l}\text { Equipment failure from static electricity buildup at low humidity points } \\
\text { Condensation formation at high humidity points }\end{array}$ \\
\hline Liquid leaks & Liquid damage to floors, cabling and equipment Indication of CRAC problems \\
\hline Human error and personnel access & $\begin{array}{l}\text { Equipment damage and data loss } \\
\text { Equipment downtime } \\
\text { Theft and sabotage of equipment }\end{array}$ \\
\hline Smoke or Fire & $\begin{array}{l}\text { Equipment failure } \\
\text { Loss of assets and data }\end{array}$ \\
\hline Hazardous airborne contaminants & $\begin{array}{l}\text { Dangerous situation for personnel and/or UPS unreliability and failure from release of } \\
\text { hydrogen } \\
\text { Equipment failure from increased static electricity and clogging of filters/ or fans from dust } \\
\text { buildup }\end{array}$ \\
\hline
\end{tabular}

Disaster Management

Disaster management approach have gradually developed at different levels, where people are more aware that there is more to disaster management than merely reaction to events. Sound disaster management is the effective application of holistic management techniques to hazards and their relationship with vulnerability. In other words, it is the effective application of risk management techniques to all hazards and all vulnerability factors. The ultimate aim of disaster management is to manage circumstances in such a way that the outcome is not a disaster.

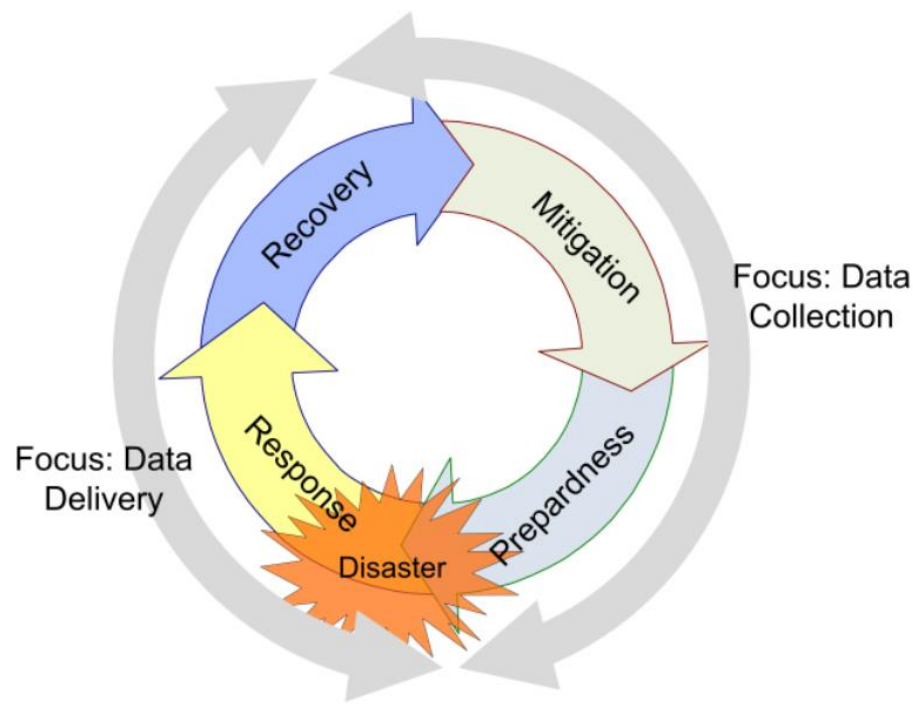

Figure 1 Disaster management phases

The area of disaster management receives increasing attention from multiple disciplines of research. A key role of computer scientists has been in devising ways to manage and analyze the data produces in disaster management situations. Disaster management has been attracting a lot of attention by many research communities, including Computer Science, Environmental Sciences, Health Sciences and Business. There are certain features that desirable for management of almost all disaster such as prevention, advance warning, early detection, analysis of the problem and assessment of scope, notification of the public and appropriate authorities, mobilization of a response, containment of damage and lastly relief and medical care for those affected [7]. Furthermore, disaster management can be divided into the 
following four phases like Figure 1; preparedness, mitigation, response and recovery. Mitigation efforts are long-term measures that attempt to prevent hazards from developing into disasters altogether, or to reduce the effects of disasters when they occur. The features of disaster management approach can be refer to Table 3 .

Table 3 Features of the previous disaster management approach

\begin{tabular}{|c|c|c|}
\hline Journal & Disaster Management Approach & Features \\
\hline $\begin{array}{l}\text { Mansourian et. al. , } \\
2005\end{array}$ & $\begin{array}{l}\text { Spatial Data Infrastructure (SDI) } \\
\text { on web-based system }\end{array}$ & Involved data mining (DM) and decision support (DS) \\
\hline Hristidis et. al. , 2010 & $\begin{array}{l}\text { Investigation on disaster related } \\
\text { situations data source. }\end{array}$ & $\begin{aligned} & 5 \text { data analysis technologies of disaster related situations: } \\
& \text { 1. } \text { Information extraction (IE) } \\
& \text { 2. } \text { Information retrieval (IR) } \\
& \text { 3. } \text { Information filtering (IF) } \\
& \text { 4. } \text { Data mining (DM) } \\
& \text { 5. } \text { Decision support (DS) }\end{aligned}$ \\
\hline Rodriguez et. al, 2009 & $\begin{array}{l}\text { decision support } \\
\text { system (DSS) data-based } \\
\text { prototype }\end{array}$ & $\begin{array}{l}\text { Applied decision support (DSS) methodology which provides damage } \\
\text { assessment for multiple disaster scenarios to support } \\
\text { Humanitarian NGOs involved in response to natural disasters. }\end{array}$ \\
\hline Kapucu, Garayev, 2011 & $\begin{array}{l}\text { collaborative decision-making } \\
\text { in emergency and disaster } \\
\text { management on the Emergency } \\
\text { Management } \\
\text { Assistance Compact's (EMAC) } \\
\text { response to the catastrophic } \\
\text { disasters Hurricanes Katrina and } \\
\text { Rita in } 2005 \text {. }\end{array}$ & $\begin{array}{ll}\text { Decision making process involved analyzed in the context of: } \\
\text { 1. } \\
\text { 2. Information extraction (IE) } \\
\text { 3. } & \text { Information retrieval (IR) } \\
& \text { (IF) filtering (IF) }\end{array}$ \\
\hline Karnatak et. Al, 2012 & $\begin{array}{l}\text { Spatial mashup technology and } \\
\text { real time data integration }\end{array}$ & Open source Geographic Information System (GIS) \\
\hline Alamdar et. Al, 2014 & $\begin{array}{l}\text { spatial data sourcing and in situ } \\
\text { sensing as an emerging } \\
\text { technology for sourcing and } \\
\text { managing disaster information }\end{array}$ & $\begin{array}{l}\text { 1. High spatial and temporal resolution } \\
\text { 2. Wide range of data } \\
\text { 3. }\end{array}$ \\
\hline
\end{tabular}

\subsection{CONCEPTUAL FRAMEWORK}

The conceptual framework had been details in Figure 2 by showing the flow related in this research paper. The research flow was built to support our research from the conceptual and theoretical perspective. It is based on main components of the chosen theories. 


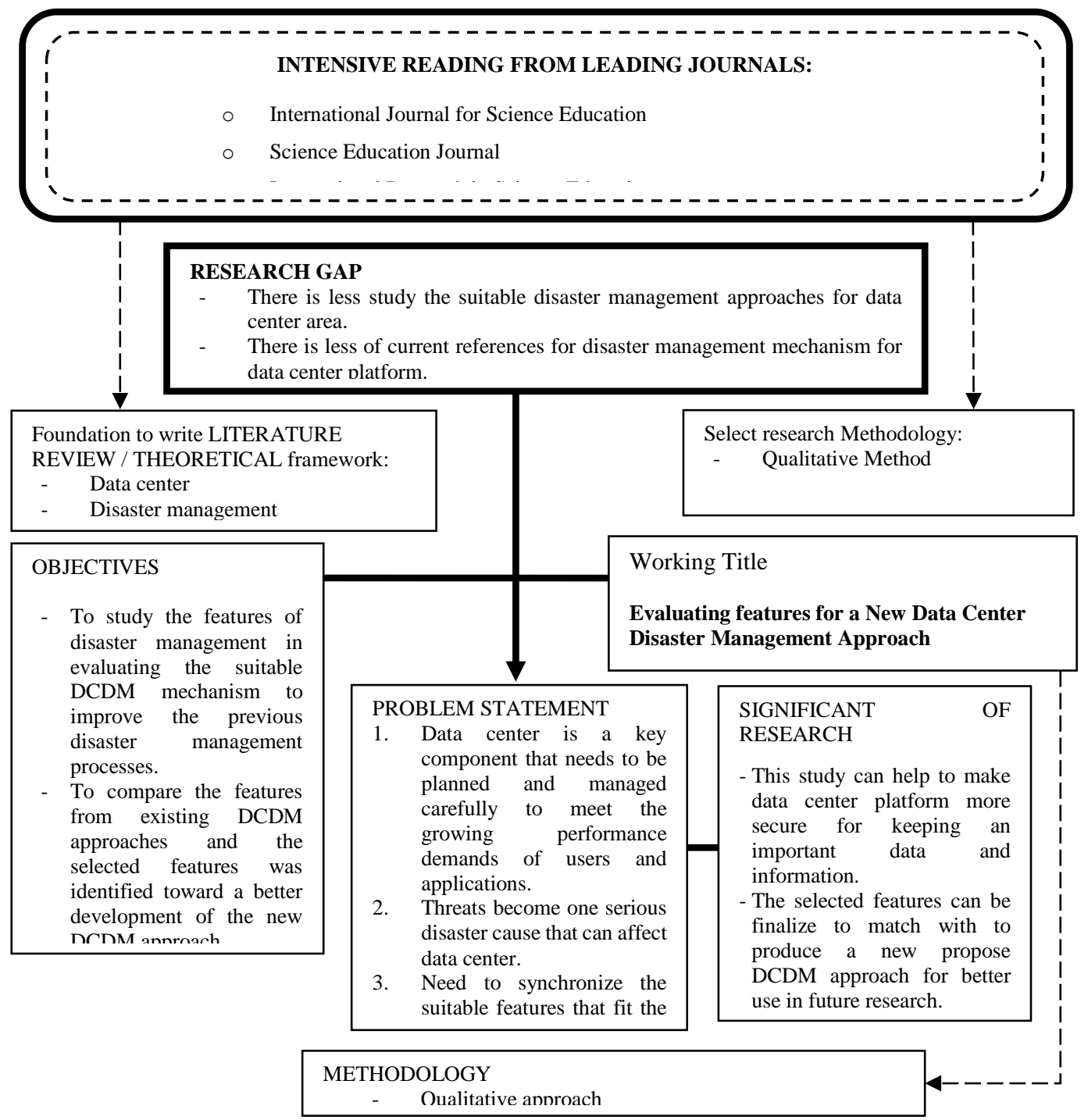

Figure 2 Research flow for this study

\subsection{RESULTS AND DISCUSSION}

In this section, list of disaster management approaches and it features is discussed. Refer to Table 4, there are nine features had been discovered according to the different approaches getting from previous researches. The most familiar features related to data in data center platform are Data Mining (DM), Decision Support (DS), Information Extraction (IE), Information Retrieval (IR), and Information Filtering (IF). After these several studies, the investigation on disaster related situations data source have highest selection features among others which is DM, DS, IE, IR and IF. The collaborative decision-making (EMAC), had choose three similar features from the five selected features by investigation on disaster management approach related study. Based on the features list in Table 4, this paper is proposing study on those features because of order in completing a selection features for an efficient data center disaster management approach are needed to choose as a pilot studies later on. Based on the features selection, this research come out with several reason on why it is become an efficiently features selection for data center disaster management approach. The reasons are can get details data source process, decision support provide better disaster assessment, some approach come out with collaborative decision-making, produce real time data integration and better sourcing and managing disaster information. 
Table 4 List of disaster management approaches and it features

\begin{tabular}{|c|c|c|c|c|c|c|c|c|c|}
\hline Features & DM & DS & IE & IR & IF & GIS & $\begin{array}{c}\text { High spatial } \\
\text { Temporal } \\
\text { resolution }\end{array}$ & $\begin{array}{c}\text { Wide range } \\
\text { data }\end{array}$ & $\begin{array}{c}\text { Automated } \\
\text { operation }\end{array}$ \\
\hline $\begin{array}{c}\text { Approach } \\
\begin{array}{c}\text { Spatial Data } \\
\text { Infrastructure (SDI) }\end{array}\end{array}$ & $\sqrt{ }$ & $\sqrt{ }$ & & & & & & & \\
\hline $\begin{array}{c}\text { Investigation } \\
\text { decision support } \\
\text { system (DSS) } \\
\text { collaborative } \\
\text { decision-making } \\
\text { (EMAC) }\end{array}$ & $\sqrt{\text { EMAC) }}$ & $\sqrt{ }$ & $\sqrt{ }$ & $\sqrt{ }$ & $\sqrt{ }$ & & & & \\
\hline $\begin{array}{c}\text { Spatial mashup } \\
\text { technology }\end{array}$ & & $\sqrt{ }$ & $\sqrt{ }$ & $\sqrt{ }$ & & & & \\
\hline $\begin{array}{c}\text { spatial data } \\
\text { sourcing and } \text { in situ } \\
\text { sensing }\end{array}$ & & & & & & & $\sqrt{ }$ & $\sqrt{ }$ & \\
\hline
\end{tabular}

\subsection{CONCLUSION}

Broaden thinking in order to acquire the necessary resources to properly develop a proactive plan of action to address potential catastrophic risk in a workplace is very important. Emergency and disaster management is not cheap. However, through proper planning and appropriate management of these potential guidance, the potential of the disaster in a workplace can be minimized. As a conclusion, this research can be as a helpful guidance for a new researchers to focus their area on doing data center disaster management works in future.

\section{Acknowledgement}

We would like to acknowledge the UTM GUP grant (Q.J130000.2528.05H76) for financial support towards the project.

\section{References}

Belady, C. (2007). In the Data Center, Power and Cooling Costs More Than the IT Equipment It Supports. Electronics Cooling, 1(13).

Bullock, M. (2009). Data Center Definition and Solutions. Retrieved from http://www.cio.com/article/2425545/data-center/data-center-definition-and-solutions.html Cowan, C. and Gaskins, C. (2011). Monitoring Physical Threats in the Data Center. White Paper 102, Revision 3.

Harizopoulos, S. holy Shah, M.A. Meza, J. Ranganathan, P. (2009). Energy Efficiency: The New Grail of Data Management Systems Research. Conference on Innovative Data Systems Research.

Hristidis, V. Chen, S. Li, T. Luis, S. and Deng, Y. (2010). Survey of Data Management and Analysis in Disaster Situations. The Journal of Systems and Software, 83, $1701-1714$.

Juniper Networks. (2013). Cloud-Ready Data Center Reference Architecture. Juniper Networks.

Kant, K. (2009). Data Center Evolution A Tutorial on State of the Art , Issues , and Challenges. Computer Networks, 53(17), $2939-2965$. 